\title{
Optimization of microwave vacuum drying parameters for germinated lentils based on starch digestibility, antioxidant activity and total phenolic content
}

\author{
Robbarts Nongmaithem ${ }^{*}$ And Venkatesh Meda ${ }^{a}$ \\ ${ }^{a}$ Department of Chemical and Biological Engineering, University of Saskatchewan, 57 campus drive, \\ Saskatoon, Sk S7N5A9, Canada \\ *Corresponding author \\ robbarts.n@gmail.com \\ TEL: +1-306-281-0071
}

Received: 02 September 2016; Published online: 18 April 2017

\begin{abstract}
The aim of this study was to optimize the processing parameters of pulse mode microwave-vacuum drying of germinated green and red lentils (CDC Greenland and CDC Maxim) and investigate the changes in their total phenolic content (TPC), total antioxidant activity (TAA) and In-vitro starch digestibility (SD). The lentils were germinated for 5 days and dried by a pulse mode microwavevacuum method, using $2 \mathrm{~s}$ to $8 \mathrm{~s}$ out of $10 \mathrm{~s}$ pulsed mode at $2000 \mathrm{~W}$ microwave power and varying the vacuum pressure level between 15 and $45 \mathrm{kPa}$. In-vitro starch digestibility increased significantly with increased microwave power level. The TPC and TAA appeared to vary distinctively in the two varieties of selected lentils. Vacuum pressure levels did not significantly $(\mathrm{p}>0.05)$ affect any responses. Green lentils could be dried at $8 \mathrm{~s}$ microwave power and $45 \mathrm{kPa}$ vacuum pressure and red lentils could be dried at $5.5 \mathrm{~s}$ microwave power and $42.19 \mathrm{kPa}$ vacuum pressure. The microwave-vacuum drying showed great potential for the drying of germinated lentils.
\end{abstract}

Keywords: Lentils; Germination; Microwave; Antioxidant activity; Phenolic content; Starch digestibility

\section{Introduction}

Lentils (Lens culinaris), an important legume crop, are among the oldest food cultivated for human consumption (Iqbal, Khalil, Ateeq, \& Khan, 2006). They are widely cultivated in the American and Asian subcontinents. They are consumed mainly in south-east Asian countries, middle-east, Africa and Latin America. Pulses and lentils are considered as an inexpensive and affordable source of protein and carbohydrates with other valuable nutriente (Giannakoula, Ilias, Maksimovic, Maksimovic, \& Zivanovic, 2012; Gharachorloo, Tarzi, \& Baharinia, 2013). In the context of living a healthy lifestyle, consump- tion of legumes has become a path for incorporating healthy and nutrient-rich food in our daily diets. However, there are reports indicating the presence of antinutritional compounds, such as trypsin inhibitor, $\alpha$-amylase inhibitor, tannin, phytic acids, saponins and oligosaccharides (Bhatty, 1988; Alonso, Orue, Zabalza, Grant, \& Marzo, 2000; Wang \& Daun, 2006). These antinutrients can be significantly reduced by germination and heat treatment (Mulimani \& Paramjyothi, 1994; Sampathkumar, 2011). Germination (sprouting) is an inexpensive process for removal of antinutrients and increasing nutritional quality (Vidal-Valverde et al., 
2002). Among germinated legumes, lentils contain various functional components which upon consumption may reduce or prevent risks of diabetes, cardiovascular diseases and inflammation (Chung, Liu, Hoover, Warkentin, \& Vandenberg, 2008; Caccialupi et al., 2010). In addition, consumption after germination is proven as one of the most effective methods for increasing the bioavailability of certain nutrients (Swieca, Baraniak, \& Gawlik-Dziki, 2013). Many trials have been made to modify the functional chemical composition of lentils using germination processes by varying time, illumination and elicitation (Swieca et al., 2013). During the germination process, seeds are first soaked in water before being placed under warm and humid conditions which are also ideal and optimal condition for bacterial proliferation. The germination step is the main source of contamination in sprouts; hence, consumers are recommended to cook (thermal treatment) the sprouts thoroughly before consumption (FDA, 2004). On the other hand, incorporation of germinated lentils in our daily diet can be made through breakfast cereals, snacks and extruded products for example pasta and noodles. However, germinated lentils, having higher moisture content, should be dried to desirable moisture content before further processing and value addition. Among the electrotechnology-based heating technologies, viz., radio frequency (RF), microwave (MW), ohmic and infrared (IR), microwave heating shows more promise in drying of food items (Sham, Scaman, \& Durance, 2001). Kadlec et al. (2001) reported that germination followed by microwave and hot air heat treatment of peas reduces $\alpha$-galactooligosaccharides while improving their nutritive value. With the combination of vacuum with the microwave drying system, the materials can be dried in a shorter time and at low temperatures allowing better retention of sensory attributes such as colour, texture and essential nutrients (Mitra \& Meda, 2009). Vacuum assisted microwave drying has been applied to reduce the moisture content of various plant materials, such as cranberries (Sunjka, Rennie, Beaudry, \& Raghavan, 2004), tomatoes (Durance \& Wang, 2002), garlic (Figiel, 2009), rosemary (Szumny, Figiel, Gutierrez-Ortiz, \& Carbonell-Barrachina, 2010;
Calin-Sanchez et al., 2011) Saskatoon berries (Mitra \& Meda, 2009) and sour cherries (Wojdyo, Figiel, Lech, Nowicka, \& Oszmianski, 2014). Hence, microwave assisted drying shows a potential method for drying of germinated seeds as the operation is rapid, more uniform and energy efficient as compared to conventional hot air drying.

So far, little has been reported regarding the effects of drying of germinated lentils on antioxidants and In-vitro starch digestibility. Therefore, the objective of the current study was to optimize the processing parameters of microwave-vacuum drying of germinated lentils and investigate its changes on total phenolic content, total antioxidant activity and In-vitro starch digestibility.

\section{Materials and Methods}

Green (CDC Greenland) and Red (CDC Maxim) lentil varieties were supplied by the University of Saskatchewan's Crop Development Centre (CDC), Canada. Both varieties were germinated in aluminium containers at room temperature $\left(25^{\circ} \mathrm{C}\right)$ for 5 days $(120 \mathrm{~h})$ under dark conditions after soaking in distilled water for $8 \mathrm{~h}$. Sprouts were rinsed twice a day (every $12 \mathrm{~h}$ ). The number of days of germination were selected based on preliminary trials that gave the highest antioxidant activity and starch digestibility (data not shown).

The 2,2-diphenyl-1-picrylhydrazyl (DPPH), Folin-Ciocolteu reagent, gallic acid and 6-hydroxy-2,5,7,8-tetramethychromane-2carboxylic acid (Trolox) were purchased from Sigma-Aldrich Canada Ltd. (Oakville, Ontario, Canada).

\subsection{Experimental design of microwave-vacuum drying}

A statistical experimental design based on central composite rotate design (CCRD) was employed to analyze the effect of microwave-vacuum drying of germinated lentils using the software Design expert 8.0.7.1 (Stat-Ease, Minneapolis, USA). A microwave vacuum (MV) dryer (Model: VMD 1.8, EnWave ${ }^{\mathrm{TM}}$ corporation, Vancouver, BC, Canada) was employed for drying the germi- 
nated lentils. The dryer is capable of producing $2000 \mathrm{~W}$ microwave power continuously, however it can also be used in pulsed mode by supplying microwave power for $0-10 \mathrm{~s}$ out of $10 \mathrm{~s}$, where $10 \mathrm{~s}$ out of $10 \mathrm{~s}$ served as continuous mode. We used pulsed mode microwave power of $2-8 \mathrm{~s}$ out of $10 \mathrm{~s}$ and constant vacuum pressure of $15-45$ $\mathrm{kPa}$ as independent parameters, each in 5 levels. Therefore, a total of 13 experiments were conducted for each lentil variety. Samples of $300 \mathrm{~g}$ were dried to $10 \pm 2 \%$ moisture content (wet basis) using a perforated polypropylene cylindrical container rotating at $10 \mathrm{rpm}$. The actual and coded values of experimental design are shown in Table 1. The input range was selected based on initial trials to avoid burning of samples. The samples were ground using a multipurpose grinding mill with $1 \mathrm{~mm}$ diameter sieve, and stored at $-20{ }^{\circ} \mathrm{C}$ in a sealable polypropylene bag for their chemical analysis. All the experiments were conducted in triplicate.

The following second order polynomial response surface model was fitted to each of the response for analysis, as below:

$Y=\beta_{0}+\sum_{i=1}^{k} \beta_{i} X_{i}+\sum_{i=1}^{k} \beta_{i i} X_{i}^{2}+\sum_{i=1 i<j}^{k-1} \sum_{j=2}^{k} \beta_{i j} X_{i} X_{j}$

where, $Y$ is response, $\beta_{0}, \beta_{i}, \beta_{i} i$, and $\beta_{i} i$ are regression coefficients of the constant, linear, quadratic and interaction terms, respectively, and $X_{i}$ and $X_{j}$ are codes of independent variables and $k$ is the number of variables. $X_{i}$ and $X_{j}$ were replaced by $\mathrm{A}$ and $\mathrm{B}$ which signify microwave power and vacuum pressure, respectively. A sequential model sum of square (type I) was carried out to select the final model, where a quadratic model was suggested to fit the responses as cubic and higher order polynomial models were aliased. The goodness-of-fit of the model was measured by coefficient of determination $\left(\mathrm{R}^{2}\right)$. The adequacy of the quadratic models was confirmed by analysis of variance (ANOVA) using Fisher Test value (F-value) and lack of fit.

The optimization of process variables was based on maximum values of all the responses i.e. total phenolic content (TPC), total antioxidant activity (TAA) and In-vitro starch digestibility (SD). In the software, responses can be assigned to different importance levels, where the importance level varies from 1 to 5 . Therefore, the process variables were optimized based on higher desir- ability of maximum TAA and SD (importance level: 5) as compare to maximum TPC (importance level: 3).

Table 1: Actual and coded value of experimental design

\begin{tabular}{ccc}
\hline $\begin{array}{c}\text { MW power, } \\
\text { s }\end{array}$ & $\begin{array}{c}\text { Vacuum pressure, } \\
\mathrm{kPa}\end{array}$ & $\begin{array}{c}\text { Coded } \\
\text { values }\end{array}$ \\
\hline 0.757 & 8.79 & -1.41 \\
2 & 15 & -1 \\
5 & 30 & 0 \\
8 & 45 & 1 \\
9.243 & 51.21 & +1.41 \\
\hline
\end{tabular}

\subsection{Total phenolic content and total antioxidant activity}

Ground samples were extracted using $70 \%$ aqueous ethanol $(1 / 10 \mathrm{w} / \mathrm{v})$ at $25{ }^{\circ} \mathrm{C}$. The supernatants were decanted into a glass vial after centrifuging at $3500 \mathrm{rpm}$ for 10 minutes. This process was repeated three times to maximize the extraction. On third repetition, the supernatant was a clear solution. The extracts were stored at $-20{ }^{\circ} \mathrm{C}$ for further analysis.

The TPC was determined based on the colour reaction of Folin-Ciocolteu reagent with hydroxyl group (Swieca, Seczyk, \& Gawlik-Dziki, 2014). The absorbance was measured using a spectrophotometer (Model: 6305, Jenway, Bibby Scientific Limited, Staffordshire, UK) at $765 \mathrm{~nm}$ and total phenolic content were expressed in terms of gallic acid equivalent (GAE) in $\mathrm{mg} / \mathrm{g}$ DM. For TAA, a 2,2-diphenyl-1-picrylhydrazyl (DPPH) stock solution of $500 \mu \mathrm{M}$ was used. TAA was determined according to the procedures described in Mitra, Meda, and Green (2013). The absorbance was measured at $517 \mathrm{~nm}$ for both samples and blank. The spectrophotometer was calibrated using distilled water and $70 \%$ methanol for TPC and TAA, respectively. Percentage DPPH inhibition was determined using following the equation:

$$
\% \text { DPPHinhibition }=\left(1-\frac{A b s_{\text {sample }}}{A b s_{\text {blank }}} \times 100\right)
$$

Abs = absorbance for both sample and blank. The level of DPPH radical scavenging capacity 
was expressed in terms of Trolox equivalent (Teq) mg per g dry matter by plotting a standard curve of DPPH inhibition against Trolox concentration.

\section{$2.3 \quad$ In-vitro starch digestibility}

In-vitro starch digestibility (\% SD) was determined using Megazyme resistant starch assay kit (K-RSTAR, Megazyme International Ireland Limited, Wicklow, Ireland). Resistant starch (RS), non resistant starch (NRS) and Total Starch (TS) content were determined by hydrolyzing the sample using pancreatic $\alpha$-amylase and amyloglucosidase for $16 \mathrm{~h}$ at $37^{\circ} \mathrm{C}$, following the procedure described in the assay kit. Absorbances were measured using the spectrophotometer at $510 \mathrm{~nm}$ against reagent bank (sodium acetate buffer and glucose oxidase/peroxidase reagent only). Total starch and In-vitro starch digestibility was measured using following equation (Swieca et al., 2013):

$$
\begin{gathered}
T S=R S+N R S \\
S D=100-\left(\frac{R S}{T S}\right) \times 100
\end{gathered}
$$

where $T S$ is the total starch, $R S$ is the Resistant starch and $N R S$ is the Non-resistant starch.

\section{Results and Discussion}

\subsection{Experimental results of microwave-vacuum drying of germinated lentils}

Both varieties of lentils (green and red) were germinated for 5 days and dried to $10 \pm 2 \%$ moisture content (wet basis) using pulsed mode microwave-vacuum (MV) dryer, from an initial moisture content of $70 \pm 5 \%$ (wet basis). The experimental data for MV drying of both germinated green and red lentils are shown in table 2 . The drying time ranged from about $130 \mathrm{~min}$ for 2 $\mathrm{s}$ MW power to $30 \mathrm{~min}$ for $8 \mathrm{~s} \mathrm{MW}$ power. Minimum drying time was about 25 min observed at 9.243 s MW power.

Maximum TPC was observed at $8 \mathrm{~s}$ MW power and $15 \mathrm{kPa}$ vacuum pressure for germinated green lentils and at $5 \mathrm{~s}$ MW power level and 30
$\mathrm{kPa}$ vacuum pressure for germinated red lentils with values of 6.82 and $5.69 \mathrm{GAE} \mathrm{mg/g} \mathrm{DM,}$ respectively. Conversely, minima were observed at $0.757 \mathrm{~s} \mathrm{MW}$ power and $30 \mathrm{kPa}$ vacuum pressure for both varieties. There is little information on drying of germinated pulses, however the increase in TPC with increased microwave power level was similar to the MW drying of other food commodities such as sour cherries (Wojdyo et al., 2014), red pepper (Vega-Galvez et al., 2009) and Kiwi (Kaya, Aydm, \& Kolayli, 2010). For total antioxidant activity (TAA), minimum and maximum values were observed at similar processing parameters as for TPC for both varieties. the maximum value of TAA for germinated green lentils was $10.12 \mathrm{Teq} \mathrm{mg} / \mathrm{g} \mathrm{DM}$ and a minimum of 3.67 Teq $\mathrm{mg} / \mathrm{g}$ DM, while $11.57 \mathrm{Teq} \mathrm{mg} / \mathrm{g}$ DM and $6.75 \mathrm{Teq} \mathrm{mg} / \mathrm{g}$ DM were found for red lentils. This showed that there is a good relationship between TPC and TAA. The reduction and a similar relationship between TPC and TAA were also observed in drying of Thai red curry powder (Inchuen, Narkrugsa, \& Pornchaloempong, 2010), goldenberry (Izli, Yildiz, Unal, Isik, \& Uylaser, 2014) and other fruits (Sultana, Anwar, Ashraf, \& Saari, 2012). It can also be noted that the TAA of germinated red lentils was higher than green lentils at same processing conditions, except for runs 2, 4 and 6 . While the TPC of green lentils was higher than for the red ones at same processing conditions, except for runs 8, 9 and 11 . In the case of In-vitro starch digestibility (SD), the percent reduction from maximum to minimum in both the lentil varieties was much less, being $3.39 \%$ and $4.99 \%$ for germinated green and red lentils, respectively. Maximum SD was observed at $9.243 \mathrm{~s}$ MW power and $30 \mathrm{kPa}$ vacuum pressure for green lentils and $8 \mathrm{~s} \mathrm{MW}$ power and $45 \mathrm{kPa}$ vacuum pressure for germinated red lentils. In contrast, minimum SD was observed at $0.757 \mathrm{~s}$ MW power and $30 \mathrm{kPa}$ vacuum pressure for both varieties. Similar effects of microwave power were reported after drying of germinated peas (Kadlec et al., 2001) and drying of barley (Emami, Perera, Meda, \& Tyler, 2012). In-vitro SD of germinated green lentils was higher than germinated red lentils after microwave drying. 
48 Nongmaithem and Meda

Table 2: Experimental design and data obtained for microwave-vacuum drying of germinated lentils

\begin{tabular}{|c|c|c|c|c|c|c|c|c|}
\hline \multirow[b]{2}{*}{ Run } & \multirow[b]{2}{*}{$\begin{array}{c}\text { MW } \\
\text { power, } \\
\text { s }\end{array}$} & \multirow[b]{2}{*}{$\begin{array}{c}\text { Vacuum } \\
\text { pr., } \\
\mathrm{kPa}\end{array}$} & \multicolumn{3}{|c|}{ Green lentil } & \multicolumn{3}{|c|}{ Red Lentil } \\
\hline & & & $\begin{array}{c}\text { TPC, } \\
\text { GAE } \\
\mathrm{mg} / \mathrm{g} \text { DM }\end{array}$ & $\begin{array}{c}\text { TAA, } \\
\text { Teq } \\
\text { mg/g DM }\end{array}$ & $\begin{array}{c}\mathrm{SD} \\
\%\end{array}$ & $\begin{array}{c}\text { TPC, } \\
\text { GAE } \\
\mathrm{mg} / \mathrm{g} \mathrm{DM}\end{array}$ & $\begin{array}{c}\text { TAA, } \\
\text { Teq } \\
\mathrm{mg} / \mathrm{g} \mathrm{DM}\end{array}$ & $\begin{array}{c}\mathrm{SD}, \\
\%\end{array}$ \\
\hline 1 & 2 & 15 & 3.88 & 5.44 & 91.03 & 3.08 & 7.01 & 86.54 \\
\hline 2 & 8 & 15 & 6.82 & 10.12 & 92.34 & 4.91 & 8.77 & 88.49 \\
\hline 3 & 2 & 45 & 4.24 & 6.29 & 91.47 & 3.14 & 9.06 & 86.32 \\
\hline 4 & 8 & 45 & 6.3 & 9.67 & 92.43 & 3.94 & 8.43 & 88.79 \\
\hline 5 & 0.757 & 30 & 3.65 & 3.67 & 90.1 & 3.09 & 6.75 & 84.36 \\
\hline 6 & 9.243 & 30 & 6.02 & 9.38 & 93.26 & 3.43 & 8.1 & 87.05 \\
\hline 7 & 5 & 8.79 & 6.75 & 5.47 & 91.74 & 5.43 & 11.08 & 86.8 \\
\hline 8 & 5 & 51.21 & 5.21 & 10.09 & 92.31 & 5.56 & 10.46 & 88.56 \\
\hline 9 & 5 & 30 & 5.49 & 7.32 & 92.3 & 5.67 & 11.35 & 87.23 \\
\hline 10 & 5 & 30 & 5.51 & 7.11 & 92.16 & 5.49 & 11.02 & 87.87 \\
\hline 11 & 5 & 30 & 5.59 & 7.79 & 91.52 & 5.67 & 11.23 & 87.02 \\
\hline 12 & 5 & 30 & 5.52 & 6.34 & 92.78 & 5.43 & 11.14 & 87.14 \\
\hline 13 & 5 & 30 & 6.03 & 7.46 & 92.75 & 5.69 & 11.57 & 86.96 \\
\hline
\end{tabular}

\subsection{Statistical analysis and model fitting using RSM}

The values of TPC, TAA and SD at different microwave (MW) and vacuum pressure levels were fitted to a second order polynomial response surface model and their significance assessed using ANOVA. Estimated coefficients of process parameters, $\mathrm{R}^{2}$ and adjusted $\mathrm{R}^{2}$ of the models developed are shown in table 3 . Lack of fit, Fvalue and $\mathrm{p}$-value of individual processing parameters of microwave vacuum drying of germinated green and red lentils are listed in table 4 and 5 , respectively. The models developed for all the responses were significant $(\mathrm{p}<0.05)$. The $\mathrm{R}^{2}$ value, which determined the variation in fitting the model, was higher than 0.8 for all the models. In addition, the adjusted $\mathrm{R}^{2}$ indicated the percentage of variation explained only by the independent variables that actually affected the dependent variable. The minor difference between $\mathrm{R}^{2}$ and the adjusted $\mathrm{R}^{2}$ is desirable since it means that the model's ability to explain data was not diminished with inclusion of a number of covariates/factors. Since the models developed were significant with higher $\mathrm{R}^{2}$ values, they could be used to predict and explain the changes made during pulsed mode microwave-vacuum drying of the germinated lentils (within the range).

The F-value and P-value of TPC of green lentil $\left(Y_{11}\right)$, which indicate the significance of the model developed, were 14.49 and 0.0014 respectively, which implied that the model was significant. Similarly, other responses, TAA $\left(\mathrm{Y}_{12}\right)$ and $\mathrm{SD}\left(\mathrm{Y}_{13}\right)$ of germinated green lentils with F-value of 8.24 and 5.61 respectively were significant $(\mathrm{p}<0.05)$. In $\mathrm{Y}_{11}$, only microwave power level (A) and $\mathrm{A}^{2}$ were significant. This showed that TPC was significantly $(\mathrm{p}<0.05)$ influenced by microwave power only. Similarly, for $\mathrm{Y}_{12}$ and $\mathrm{Y}_{13}$, only term A was significant and vacuum pressure was less effective in altering total antioxidant activity and In-vitro starch digestibility (SD) during pulsed mode microwave vacuum drying of germinated lentils. The lack of fit for all the models of green lentil had p-values greater than 0.05. Insignificant lack of fit implies that the model can be well fitted to describe the response. In case of germinated red lentils, the lack of fit for TPC $\left(\mathrm{Y}_{21}\right)$ and TAA $\left(\mathrm{Y}_{22}\right)$ was significant when all the terms in quadratic model were included. Removal of insignificant model terms improved the adequacy of a model. Unfortunately, even after application of backward 
elimination regression, lack of fit was significant for both $\mathrm{Y}_{21}$ and $\mathrm{Y}_{22}$. However, predicted $\mathrm{R}^{2}$ for $\mathrm{Y}_{22}$ was 0.6827 , the difference in corresponding adjusted $\mathrm{R}^{2}$ and predicted $\mathrm{R}^{2}$ was within the limit of 0.2 which indicated that the model had sufficient capabilities to predict their responses (DeLoach \& Ulbrich, 2007; Alshaibani, Yaakob, Alsobaai, \& Sahri, 2014). F-values of $\mathrm{Y}_{21}, \mathrm{Y}_{22}$ and $\mathrm{Y}_{23}$ were $30.41,30.02$ and 6.83 , respectively, with p-values less than 0.05 indicating the models were significant. Model terms $\mathrm{A}$ and $\mathrm{A}^{2}$ were significant $(\mathrm{p}<0.05)$ for $\mathrm{Y}_{21}$ while only the $\mathrm{A}^{2}$ and A term were significant for $\mathrm{Y}_{22}$ and $\mathrm{Y}_{23}$, respectively, which were similar to the findings for green lentils. None of the interaction terms (AB) was significant which implied that microwave power level and vacuum pressure level did not have any significant interaction in altering TPC, TAA or SD.

\subsection{Response surface analysis}

Response surfaces, shown in Fig. 1, were plotted to help visualize the effects of microwave power, vacuum pressure and their interactions on TPC, TAA and SD of germinated green and red lentils. It was observed that TPC, TAA and SD of germinated green lentils increased with increased microwave power and vacuum pressure, and microwave power level was more significant for changes in the responses. In all the responses, the interaction terms were not affected significantly. However, for germinated red lentils, the TPC and TAA increased with increasing microwave power up to $5 \mathrm{~s}$ microwave power level and started to descend with increasing microwave power level. There was a gradual rise in TPC and TAA with increasing vacuum pressure level, but only the square of microwave pressure level was significant. Similar to the case of germinated green lentils, the interaction terms of microwave power and vacuum pressure level did not affect significantly $(\mathrm{p}>0.05)$ the TPC and TAA. The increase in TPC and TAA with increasing microwave and vacuum pressure level may have been due to shorter drying time and lower temperature of drying. Microwave energy causes volumetric heating resulting in heat transfer from inside to the surface while higher vacuum pres- sure helps lower evaporating temperature which ultimately results in faster drying. Prolonged exposure to this type of drying technique may result in loss of volatile material and oxidative reduction of phenolic compounds and these phenomena (Mitra et al., 2013). Lower power MW drying resulted in longer drying time and lower temperatures. At lower MW power, it is possible that oxidative enzymes such as polyphenoloxidases and peroxidases were not inactivated immediately, resulting in degradation of phenolic compounds during long exposure. Moreover, most of the antioxidants are phenolic compounds present in the seed coats of lentils, which are easily accessible to oxidative processes (Khan, Jacobsen, \& Eggum, 1979). There are reports of positive relationships between phenolics and antioxidant activity in lentils (Cevallos-Casals \& Cisneros-Zevallos, 2010; Swieca, 2015) and thus, the reduction of antioxidant activity can be explained by oxidative processes and long exposure of lentils during drying process. The difference in trends of TPC and TAA among the varieties studied may be due to differences in size, as the surface area for oxidation varied and also due to differences in the types and amount of phenolics present in them.

In-vitro starch digestibility of both varieties of germinated lentils also increased with the increase in microwave power similar and the findings matched those of Kadlec et al. (2001) in the drying of germinated peas and Emami et al. (2012) in the drying of barley. It has been reported that starch might degrade due to starch fragmentation (starch micronization) during irradiation resulting in increasing sugar content of legumes and cereal crops (Khan et al., 1979; Gonzalez \& Perez, 2002). Emami, Meda, Pickard, and Tyler (2010) also reported that micronization increases the amount of readily digestible starch and decreases resistant starch and slowly digestible starch. This means the In-vitro digestibility of starch will increase with increased dose of microwave energy. In addition, higher microwave power may decrease the levels of antinutritional compounds leading to higher digestibility of starch.

The optimum processing parameters generated based on maximizing TPC, TAA and SD with maximum importance given to TAA and SD are 
Table 3: Estimated coefficients of process parameters, R2 and adjusted R2 of the models

\begin{tabular}{ccccccc}
\hline & \multicolumn{6}{c}{ Estimated coefficients } \\
\hline \multirow{3}{*}{ Gactor } & TPC, lentils & TAA, & SD, & TPC, & TAA, & SD, \\
& $\mathrm{Y}_{11}$ & $\mathrm{Y}_{12}$ & $\mathrm{Y}_{13}$ & $\mathrm{Y}_{21}$ & $\mathrm{Y}_{22}$ & $\mathrm{Y}_{23}$ \\
Intercept & 5.63 & 7.20 & 92.30 & 5.45 & 10.955 & 87.24 \\
A-MW & 1.04 & 2.02 & 0.84 & 0.39 & 0.38 & 1.03 \\
B-Pressure & -0.29 & 0.87 & 0.17 & - & - & 0.32 \\
AB & -0.22 & -0.33 & -0.09 & - & - & 0.13 \\
$\mathrm{~A}^{2}$ & -0.42 & -0.16 & -0.32 & -1.29 & -2.06 & -0.56 \\
$\mathrm{~B}^{2}$ & 0.15 & 0.47 & -0.15 & - & - & 0.43 \\
$\mathrm{R}^{2}$ & 0.9119 & 0.8548 & 0.8003 & 0.8588 & 0.8572 & 0.8299 \\
Adj. $\mathrm{R}^{2}$ & 0.8490 & 0.7511 & 0.6576 & 0.8359 & 0.8287 & 0.7084 \\
\hline
\end{tabular}

Table 4: Lack of fit, F-value and P-value of individual processing parameters of green lentils

\begin{tabular}{ccccccc}
\hline & \multicolumn{2}{c}{$\mathrm{Y}_{11}$} & \multicolumn{2}{c}{$\mathrm{Y}_{12}$} & \multicolumn{2}{c}{$\mathrm{Y}_{13}$} \\
\hline Source & F-value & P-value & F-value & P-value & F-vale & P-value \\
Model & 14.49 & $0.0014^{*}$ & 8.24 & $0.0076^{*}$ & 5.61 & $0.0215^{*}$ \\
A-MW & 56.76 & $0.0001^{*}$ & 32.83 & $0.0007^{*}$ & 23.69 & $0.0018^{*}$ \\
B-Pressure & 4.45 & 0.0729 & 6.06 & 0.0433 & 0.93 & 0.3667 \\
AB & 1.26 & 0.2986 & 0.43 & 0.5347 & 0.13 & 0.7312 \\
$\mathrm{~A}^{2}$ & 8.02 & $0.0253^{*}$ & 0.17 & 0.6888 & 2.97 & 0.1286 \\
B $^{2}$ & 1.04 & 0.3415 & 1.55 & 0.2533 & 0.63 & 0.4536 \\
Lack of Fit & 5.57 & 0.0653 & 6.52 & 0.0509 & 0.77 & 0.5659 \\
\hline
\end{tabular}

*Significant at $\mathrm{P} \leq 0.05$

Table 5: Lack of fit, F-value and P-value of individual processing parameters of red lentils

\begin{tabular}{ccccccc}
\hline & \multicolumn{2}{c}{$\mathrm{Y}_{21}$} & \multicolumn{2}{c}{$\mathrm{Y}_{22}$} & \multicolumn{2}{c}{$\mathrm{Y}_{23}$} \\
\hline Source & F-value & P-value & F-value & P-value & F-vale & P-value \\
Model & 30.41 & $<0.0001^{*}$ & 30.02 & $<0.0001^{*}$ & 6.83 & $0.0127^{*}$ \\
A-MW & 5.66 & $0.0387^{*}$ & 2.32 & 0.1601 & 21.71 & $0.0023^{*}$ \\
B-Pressure & - & - & - & - & 2.12 & 0.1889 \\
AB & - & - & - & - & 0.17 & 0.6894 \\
$\mathrm{~A}^{2}$ & 55.18 & $<0.0001^{*}$ & 57.81 & $<0.0001^{*}$ & 5.58 & 0.0502 \\
B $^{2}$ & - & - & 4.11 & - & 3.28 & 0.1130 \\
Lack of Fit & 23.75 & $0.0043^{*}$ & 18.81 & $0.0067^{*}$ & 5.45 & 0.0670 \\
\hline
\end{tabular}

*Significant at $\mathrm{P} \leq 0.05$

IJFS | April 2017 | Volume 6 | pages 44-55 
Microwave vacuum drying of germinated lentils |51

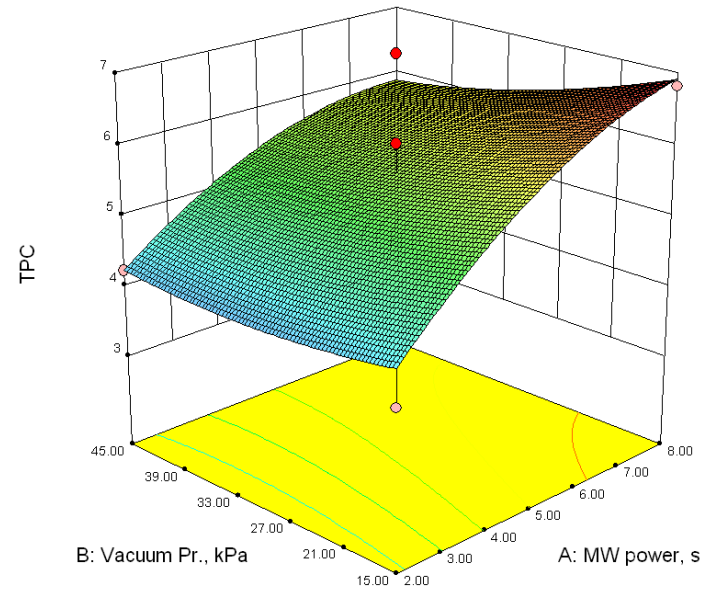

(A)

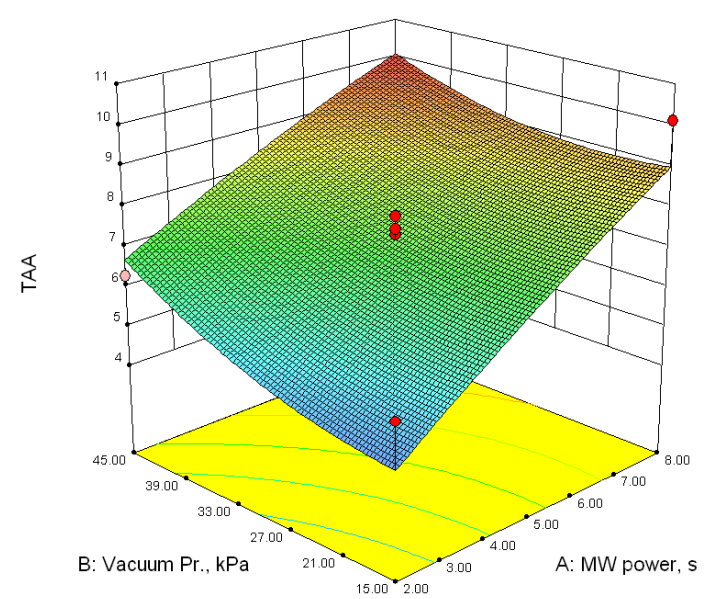

(C)

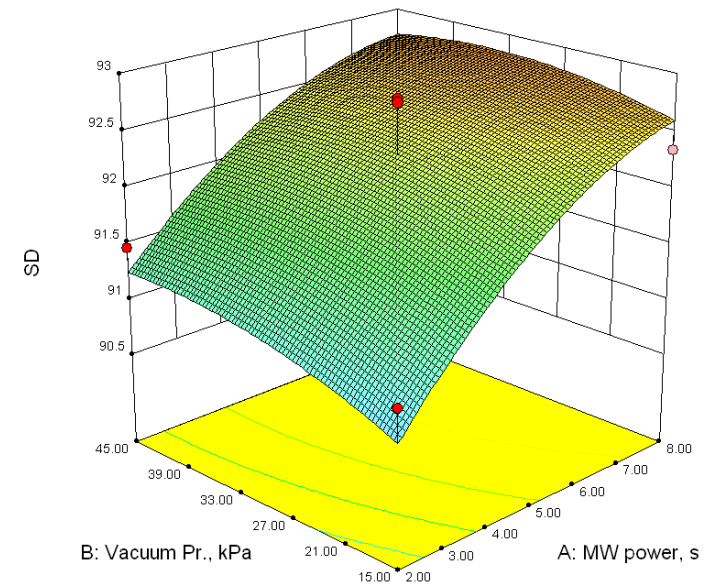

(E)

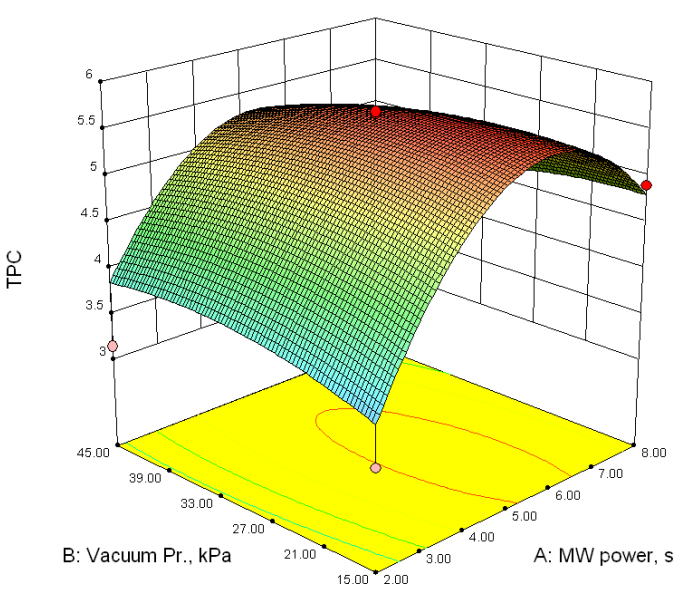

(B)

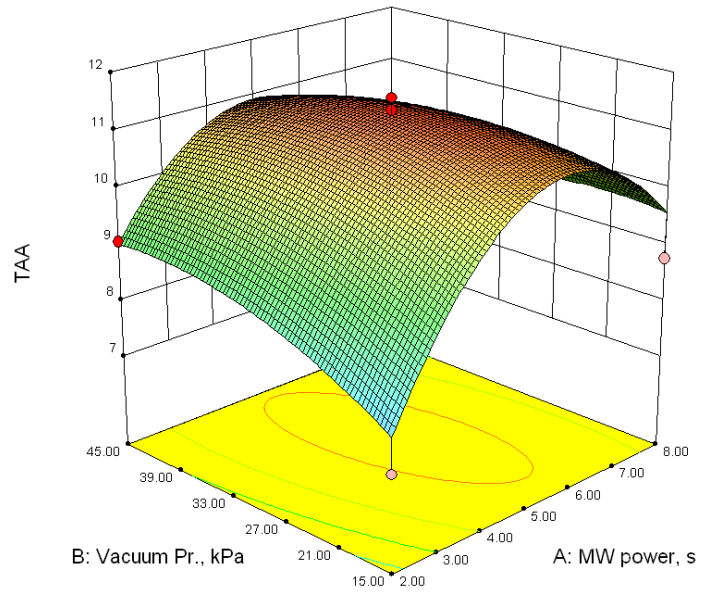

(D)

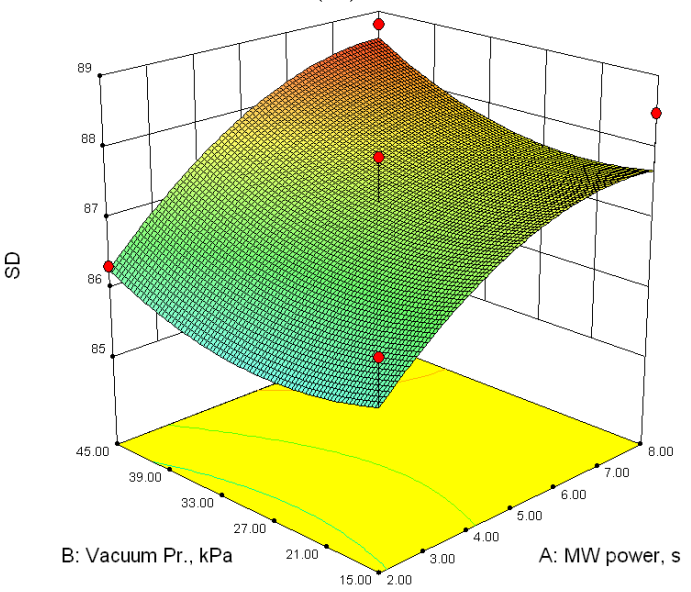

(F)

Figure 1: Response surface plots showing the effects of pulse mode microwave (MW) power and vacuum pressure on TPC (A,B), TAA (C,D) and SD (E,F) of germinated lentils. (left column : green lentil; right column : red lentil). 
Table 6: Optimum processing parameters generated for MV drying of germinated lentils

\begin{tabular}{cccccccccc}
\hline $\begin{array}{c}\text { Lentil } \\
\text { Variety }\end{array}$ & $\begin{array}{c}\text { MW } \\
\text { power, s }\end{array}$ & $\begin{array}{c}\text { Vacuum } \\
\text { pr., kPa }\end{array}$ & \multicolumn{2}{c}{ GAE mg/g DM } & \multicolumn{2}{c}{ Teq mg/g DM } & SD, \% & \multirow{2}{*}{ Desirability } \\
\hline & & & Pred & Expt & Pred & Expt & Pred & Expt & \\
\hline Green & 8 & 45.00 & 5.89 & 6.28 & 10.07 & 9.68 & 92.76 & 92.50 & 0.86 \\
Red & 5.507 & 42.19 & 5.38 & 5.51 & 10.98 & 11.13 & 87.96 & 87.61 & 0.85 \\
\hline
\end{tabular}

Pred: Predicted ; Expt: Experimental (Validation)

shown in table 6 . Samples were treated at optimum process conditions to validate the values of optimum processing parameters. The variations with the predicted and observed values were less than $10 \%$ (Table 6 ). Therefore, the models generated could be employed for determining changes during drying of germinated green lentil (CDC Greenland) and red lentil (CDC Maxim) in the given processing range. Raw samples (before germination) had TPC values of 7.48 and 6.42 GAE mg/g DM for green and red lentils, respectively, while TAA values were 10.44 and $12.87 \mathrm{Teq} \mathrm{mg} / \mathrm{g} \mathrm{DM}$, respectively for green and red lentils. These results show that the reduction in TPC and TAA of the lentils after processing at optimum conditions was about $16 \%$ and $13 \%$, respectively. For the SD (raw sample having SD of $64.95 \%$ and $62.18 \%$ for green and red lentils respectively), there was an increase in starch digestibility up to about $40 \%$, showing that microwave vacuum drying after germination process increased starch digestibility of lentils with only a small reduction in TPC and TAA. Aguilera et al. (2009) reported that starch digestibility may be improved by initial soaking and thermal treatment due to gelatinization of starch granules and reduction of antinutritional compounds from the raw seed.

\section{Conclusions}

In drying of germinated lentils using pulsed mode microwave-vacuum drying technique, starch digestibility increased significantly with increased microwave power level. The TPC and TAA may have varied distinctively with variation in lentil variety. Vacuum pressure levels did not affect significantly $(\mathrm{p}>0.05)$ the responses that were stud- ied. For the optimum drying of 5 days germinated lentils in pulsed mode microwave vacuum condition, green lentils could be dried at a pulse rate of $8 \mathrm{~s}$ out of $10 \mathrm{~s}$ microwave power of $2000 \mathrm{~W}$ and $45 \mathrm{kPa}$ constant vacuum pressure, whereas red lentils could be dried at a pulse rate of 5.5 $\mathrm{s}$ out of $10 \mathrm{~s}$ microwave power of $2000 \mathrm{~W}$ and $42.19 \mathrm{kPa}$ constant vacuum pressure. The mathematical model generated for drying of germinated lentils could be used for scaling up the process. Germination followed by microwave vacuum drying could be a promising path to increase the digestibility of starch with minimum changes in phenolics and antioxidant activity. Moreover, this technology could also be employed for drying other pulses for further processing. The dried germinated lentils obtained could be treated as a raw material for further utilized as ingredients in bakery, extruded snacks and other value added healthy food products. However, further studies may be required for new product development.

\section{Acknowledgements}

We gratefully acknowledge Department of Chemical and Biological Engineering and Supervisor's Research Grant, University of Saskatchewan for funding this research. Also, we would like to thank University of Saskatchewan's Crop Development Centre (CDC) for providing the lentil seeds.

\section{References}

Aguilera, Y., Martin-Cabrejas, M. A., Benitez, V., Molla, E., Lopez-Andreu, F. J., \& Esteban, R. M. (2009). Changes in carbo- 
hydrate fraction during dehydration process of common legumes. Journal of Food Composition and Analysis, 22(7-8), 678683. doi:10.1016/j.jfca.2009.02.012

Alonso, R., Orue, E., Zabalza, M. J., Grant, G., \& Marzo, F. (2000). Effect of extrusion cooking on structure and functional properties of pea and kidney bean proteins. Journal of the Science of Food and Agriculture, 80(3), 397-403. 3rd International Workshop on Antinutritional Factors in Legume Seeds and Rapeseed, WAGENINGEN, NETHERLANDS, 1996. doi:10.1002/1097-0010(200002)80:3/397:: AID-JSFA542>3.0.CO;2-3

Alshaibani, A. M., Yaakob, Z., Alsobaai, A. M., \& Sahri, M. (2014). Optimization of pdb/gamma-al2o3 catalyst preparation for palm oil hydrogenation by response surface methodology (rsm). Brazilian Journal of Chemical Engineering, 31(1), 69-78.

Bhatty, R. S. (1988). Composition and quality of lentil (lens-culinaris medik) - a review. Canadian Institute of Food Science and Technology Journal-journal De L Institut Canadien De Science Et Technologie Alimentaires, 21 (2), 144-160.

Caccialupi, P., Ceci, L. R., Siciliano, R. A., Pignone, D., Clemente, A., \& Sonnante, G. (2010). Bowman-birk inhibitors in lentil: heterologous expression, functional characterisation and anti-proliferative properties in human colon cancer cells. Food Chemistry, 120(4), 1058-1066. doi:10.1016/j . foodchem.2009.11.051

Calin-Sanchez, A., Szumny, A., Figiel, A., Jaloszynski, K., Adamski, M., \& CarbonellBarrachina, A. A. (2011). Effects of vacuum level and microwave power on rosemary volatile composition during vacuummicrowave drying. Journal of Food Engineering, 103(2), 219-227. doi:10.1016/j . jfoodeng.2010.10.018

Cevallos-Casals, B. A. \& Cisneros-Zevallos, L. (2010). Impact of germination on phenolic content and antioxidant activity of 13 edible seed species. Food Chemistry, 119(4), 1485-1490. doi:10.1016/j.foodchem.2009. 09.030
Chung, H.-J., Liu, Q., Hoover, R., Warkentin, T. D., \& Vandenberg, B. (2008). In vitro starch digestibility, expected glycemic index, and thermal and pasting properties of flours from pea, lentil and chickpea cultivars. Food Chemistry, 111(2), 316-321. doi:10.1016/j.foodchem.2008.03.062

DeLoach, R. \& Ulbrich, N. (2007). A comparison of two balance calibration model building methods. In 45th aiaa aerospace sciences meeting and exhibit, held at reno, nevada, 8-11 january (1-81). reston: american institute of aeronautics and astronautics (p. 147).

Durance, T. D. \& Wang, J. H. (2002). Energy consumption, density, and rehydration rate of vacuum microwave- and hot-air convection- dehydrated tomatoes. Journal of Food Science, 67(6), 2212-2216. doi:10. 1111/j.1365-2621.2002.tb09529.x

Emami, S., Meda, V., Pickard, M. D., \& Tyler, R. T. (2010). Impact of micronization on rapidly digestible, slowly digestible, and resistant starch concentrations in normal, high-amylose, and waxy barley. Journal of Agricultural and Food Chemistry, 58(17), 9793-9799. doi:10.1021/jf101702e

Emami, S., Perera, A., Meda, V., \& Tyler, R. T. (2012). Effect of microwave treatment on starch digestibility and physico-chemical properties of three barley types. Food and Bioprocess Technology, 5(6), 2266-2274. doi:10.1007/s11947-011-0688-2

FDA. (2004). Retrieved from http : / / www . fda . gov / Food / GuidanceRegulation / RetailFoodProtection/\%20ucm078758.htm

Figiel, A. (2009). Drying kinetics and quality of vacuum-microwave dehydrated garlic cloves and slices. Journal of Food Engineering, 94 (1), 98-104. doi:10.1016/j.jfoodeng. 2009.03.007

Gharachorloo, M., Tarzi, B. G., \& Baharinia, M. (2013). The effect of germination on phenolic compounds and antioxidant activity of pulses. Journal of the American Oil Chemists Society, 90(3), 407-411. doi:10. 1007/s11746-012-2170-3

Giannakoula, A. E., Ilias, I. F., Maksimovic, J. J. D., Maksimovic, V. M., \& Zivanovic, B. D. (2012). The effects of plant growth 
regulators on growth, yield, and phenolic profile of lentil plants. Journal of Food Composition and Analysis, 28(1), 46-53. doi:10.1016/j.jfca.2012.06.005

Gonzalez, Z. \& Perez, E. (2002). Evaluation of lentil starches modified by microwave irradiation and extrusion cooking. Food Research International, 35(5), 415-420. doi:10.1016/S0963-9969(01)00135-1

Inchuen, S., Narkrugsa, W., Pornchaloempong, P., et al. (2010). Effect of drying methods on chemical composition, color and antioxidant properties of thai red curry powder. Kasetsart Journal of Natural Science, 44, 142-151. Retrieved from http:// kasetsartjournal.ku.ac.th/kuj_files / 2010 / A1001141124058750.pdf

Iqbal, A., Khalil, I. A., Ateeq, N., \& Khan, M. S. (2006). Nutritional quality of important food legumes. Food Chemistry, 97(2), 331335. doi:10.1016/j.foodchem.2005.05.011

Izli, N., Yildiz, G., Unal, H., Isik, E., \& Uylaser, V. (2014). Effect of different drying methods on drying characteristics, colour, total phenolic content and antioxidant capacity of goldenberry (physalis peruviana 1.) International Journal of Food Science and Technology, 49(1), 9-17. doi:10.1111/ ijfs. 12266

Kadlec, P., Rubecova, A., Hinkova, A., Kaasova, J., Bubnik, Z., \& Pour, V. (2001). Processing of yellow pea by germination, microwave treatment and drying. Innovative Food Science \& Emerging Technologies, 2(2), 133-137. doi:10.1016/S1466-8564(01) 00036-4

Kaya, A., Aydm, O., \& Kolayli, S. (2010). Effect of different drying conditions on the vitamin $\mathrm{C}$ (ascorbic acid) content of hayward kiwifruits (actinidia deliciosa planch). Food and Bioproducts Processing, 88(C23), 165-173. doi:10.1016/j.fbp.2008.12.001

Khan, M. A., Jacobsen, I., \& Eggum, B. O. (1979). Nutritive value of some improved varieties of legumes. Journal of the Science of Food and Agriculture, 30(4), 395-400.

Mitra, P. \& Meda, V. (2009). Optimization of microwave-vacuum drying parameters of saskatoon berries using response surface methodology. Drying Tech- nology, 27(10), 1089-1096. doi:10.1080 / 07373930903221101

Mitra, P., Meda, V., \& Green, R. (2013). Effect of drying techniques on the retention of antioxidant activities of saskatoon berries. International Journal of Food Studies, 2(2), 224-237. doi:10.7455/ijfs/2.2.2013.a8

Mulimani, V. H. \& Paramjyothi, S. (1994). Effect of heat-treatments on trypsin chyomotrypsin inhibitor activity of red gram (cajanus-cajan 1). Plant Foods for Human Nutrition, 46(2), 103-107. doi:10.1007/ BF01088761

Sampathkumar, Y. (2011). Thermal processing effects on total phenolic content, antioxidant activity, trypsin inhibitor activity and in vitro protein digestibility of lentils (Doctoral dissertation, McGill University). Retrieved May 2, 2014. Retrieved from http : / / digitool. library. mcgill.ca / thesisfile107918.pdf

Sham, P. W. Y., Scaman, C. H., \& Durance, T. D. (2001). Texture of vacuum microwave dehydrated apple chips as affected by calcium pretreatment, vacuum level, and apple variety. Journal of Food Science, 66(9), 1341-1347. doi:10.1111/j.1365-2621.2001. tb15212.x

Sultana, B., Anwar, F., Ashraf, M., \& Saari, N. (2012). Effect of drying techniques on the total phenolic contents and antioxidant activity of selected fruits. Journal of Medicinal Plants Research, 6(1), 161-167.

Sunjka, P. S., Rennie, T. J., Beaudry, C., \& Raghavan, G. S. V. (2004). Microwaveconvective and microwave-vacuum drying of cranberries: a comparative study. Drying Technology, 22(5), 1217-1231. International Conference on Process Integration Modeling and Optimization for Energy Saving and Pollution Reduction, Hamilton, CANADA, OCT 26-29, 2003. doi:10.1081/ drt-120038588

Swieca, M. (2015). Production of ready-toeat lentil sprouts with improved antioxidant capacity: optimization of elicitation conditions with hydrogen peroxide. Food Chemistry, 180, 219-226. doi:10.1016/j . foodchem.2015.02.031 
Microwave vacuum drying of germinated lentils $\mid 55$

Swieca, M., Baraniak, B., \& Gawlik-Dziki, U. (2013). In vitro digestibility and starch content, predicted glycemic index and potential in vitro antidiabetic effect of lentil sprouts obtained by different germination techniques. Food Chemistry, 138(2-3), 1414-1420. doi:10.1016/j.foodchem.2012. 09.122

Swieca, M., Seczyk, L., \& Gawlik-Dziki, U. (2014). Elicitation and precursor feeding as tools for the improvement of the phenolic content and antioxidant activity of lentil sprouts. Food Chemistry, 161, 288295. doi:10.1016/j.foodchem.2014.04.012

Szumny, A., Figiel, A., Gutierrez-Ortiz, A., \& Carbonell-Barrachina, A. A. (2010). Composition of rosemary essential oil (rosmarinus officinalis) as affected by drying method. Journal of Food Engineering, 97(2), 253-260. doi:10.1016/j.jfoodeng. 2009.10.019

Vega-Galvez, A., Di Scala, K., Rodriguez, K., Lemus-Mondaca, R., Miranda, M., Lopez, J., \& Perez-Won, M. (2009). Effect of airdrying temperature on physico-chemical properties, antioxidant capacity, colour and total phenolic content of red pepper (capsicum annuum, 1. var. hungarian). Food Chemistry, 117(4), 647-653. doi:10.1016/j. foodchem.2009.04.066

Vidal-Valverde, C., Frias, J., Sierra, I., Blazquez, I., Lambein, F., \& Kuo, Y. H. (2002). New functional legume foods by germination: effect on the nutritive value of beans, lentils and peas. European Food Research and Technology, 215(6), 472-477. doi:10 . 1007/s00217-002-0602-2

Wang, N. \& Daun, J. K. (2006). Effects of variety and crude protein content on nutrients and anti-nutrients in lentils (lens culinaris). Food Chemistry, 95(3), 493-502. doi:10. 1016/j.foodchem.2005.02.001

Wojdyo, A., Figiel, A., Lech, K., Nowicka, P., \& Oszmianski, J. (2014). Effect of convective and vacuum-microwave drying on the bioactive compounds, color, and antioxidant capacity of sour cherries. Food and Bioprocess Technology, 7(3), 829-841. doi:10.1007/s11947-013-1130-8 